\title{
Emerging zoonotic infectious diseases: a folly of human development
}

\author{
J.C.B. Tenorio
}

Department of Veterinary Paraclinical Sciences, College of Veterinary Medicine, University of Southern Mindanao, Kabacan 9407, Cotabato, Philippines

Email address: jcbtenorio@usm.edu.ph ;Tel: (064) 5722384

Journal of Livestock Science (ISSN online 2277-6214) 13: 76-79

Received on 20/11/21; Accepted on 25/1/22; Published on 5/2/22

doi. 10.33259/JLivestSci.2022.76-79

\begin{abstract}
The accelerated pace at which human development has been set into has resulted into fast-tracking the emergence of novel diseases that affect both humans and animals. One of these is the emergence of infectious zoonotic diseases that have threatened human health since time immemorial. The emergence of Highly Pathogenic Avian Influenza (HPAI) H5:N1 from poultry in 2002, Severe acute respiratory syndrome coronavirus (SARS-CoV) from civets and bats in 2003, Middle East Respiratory Syndrome coronaviruses (MERS-CoV) from camelids in 2014, and most recently in SARS-CoV 2 or COVID-19, which reportedly came from bats, should serve as lessons that should be taken seriously. Factors that have resulted in the emergence of these illnesses include, but are not limited to, environmental destruction, illegal wildlife trade, and increasingly intensive livestock and poultry production. It is high time that humans look into efforts that prevent the emergence of these illnesses, rather than simply managing their effects. Addressing the problem through the lens of One Health is the way to go.
\end{abstract}

Keywords: COVID-19; Emerging Infectious Diseases; MERS-CoV; Zoonotic Diseases 


\section{Introduction}

The accelerated pace at which human development has been set into has resulted into fast-tracking the emergence of novel diseases that affect both humans and animals (Goenka \& Liu, 2020). Hence, it is not a surprise that every decade since the turn of the millennium has been marked by devastating infectious illnesses that had roots in the abuse of the environment, wildlife, and food animals: Highly Pathogenic Avian Influenza (HPAI) H5:N1 in 2004, Severe acute respiratory syndrome coronavirus (SARS-CoV) in 2003, H1:N1 Swine Flu in 2009; Middle East Respiratory Syndrome coronaviruses (MERS-CoV) in 2014, and most recently SARS-CoV 2 or COVID-19 (Bonilla-Aldana et al., 2020; Oboho et al., 2015; Spencer et al., 2021). This paper will succinctly discuss emerging zoonotic infectious diseases, factors that may have influenced their emergence as illnesses, and the importance of viewing these health issues thru the lens of One Health.

\section{Emerging Zoonotic Infectious Diseases}

Infectious diseases are illnesses that are caused by agents that are transmissible from an infected person, animal or through fomites to a susceptible host. Infectious agents that cause these illnesses include viruses, bacteria, fungi, and parasites (i.e., protozoans and helminths) (Oeschger et al., 2021; Tenorio and Molina, 2021a\&b). However, there are also unconventional etiologic agents like prions (i.e., infectious proteins) that causes spongiform encephalopathy (Levkovich et al., 2021). These diseases may be transmitted through the air, via aerosols, through direct contact, fomites, vehicled by food, through blood transfusion or via arthropod vectors (Tenorio and Flores, 2021; Greenhalgh et al., 2021; Athni et al., 2021). A subcategory of infectious diseases is emerging infectious diseases (EIDs). EIDs are newly discovered transmissible maladies or are infectious illnesses that have been previously reported but have since re-emerged with increasing incidence within a population in a geographical area (Frutos et al., 2021; Van Oosterhout, 2021). It has been estimated that about $75 \%$ of emerging infectious disease are zoonotic in nature - transmitted from animals to humans and vice versa (Taylor et a., 2001). Therefore, an important touchpoint in this discussion are emerging zoonoses. The five infectious diseases mentioned in the introduction that have grappled humanity are emerging zoonoses: H5:N1 HPAI from poultry, SARS-CoV from "civets and bats", H1:N1 Swine Flu from pigs, MERS-CoV from camelids, and SARS-CoV-2 allegedly from "civets and bats" (Bonilla-Aldana et al., 2020; Spencer et al., 2021; Platto et al., 2021). It has been posited that about one billion people worldwide succumb and die due to zoonotic diseases (Espinosa et al., 2020).

\section{Some factors affecting the emerging zoonotic infectious diseases}

A number of factors may have contributed to the emergence of zoonotic infectious diseases. Increased human encroachment in environments that were supposed to be wildlife habitats has led to the former being exposed to pathogens that originate from the latter animals (Barbier, 2021; Bezerra-Santos et al., 2021). Similarly, destruction of the environment and disruption of ecosystems to give way for infrastructure and economic gain has resulted to wildlife movements towards human settlements further increasing exposure risks. Illegal wildlife trade should also be noted in this discussion. These phenomena result to zoonotic spillover events (Williams et al., 2021). The previously mentioned zoonotic infectious diseases caused by Alpha coronaviruses and the extent of the devastation they have caused are testaments to the catastrophic results of wildlife zoonotic spill overs. Another perspective worthy of examination in the emergence of zoonotic diseases is the intensive production methods for food animals that have been put into place to feed the earth's growing human population (Ferreira et al., 2021; Gong et al., 2021). Intensive rearing of livestock that involve increasing densities of animals raised in confined spaces enable the spread of animal diseases at a faster pace. The high probabilities of rapid disease transmission in these animals become a grave concern when zoonotic infectious diseases are the ones wreaking havoc. The H5:N1 avian influenza outbreak in Asian countries in the early 2000s nearly crippled their growing agricultural economies (Chowdhury et al., 2020; Spencer et al., 2021). Hence, zoonotic infectious diseases like H5:N1 HPAI have disastrous effects on the animal production perhaps due to the control and elimination efforts that are enacted to control it (e.g., strict quarantine measures, stamping out programs, zoning, and trade restrictions). Risky agricultural practices, including increasingly intensive livestock and poultry production, account for more than $50 \%$ of the zoonotic infectious diseases that have decimated the human populace (Rohr et al., 2019). Therefore, the deleterious effects of zoonotic infectious diseases of livestock origin should be considered both as a human health hazard and as an agricultural production problem when crafting regional and national development policies. 


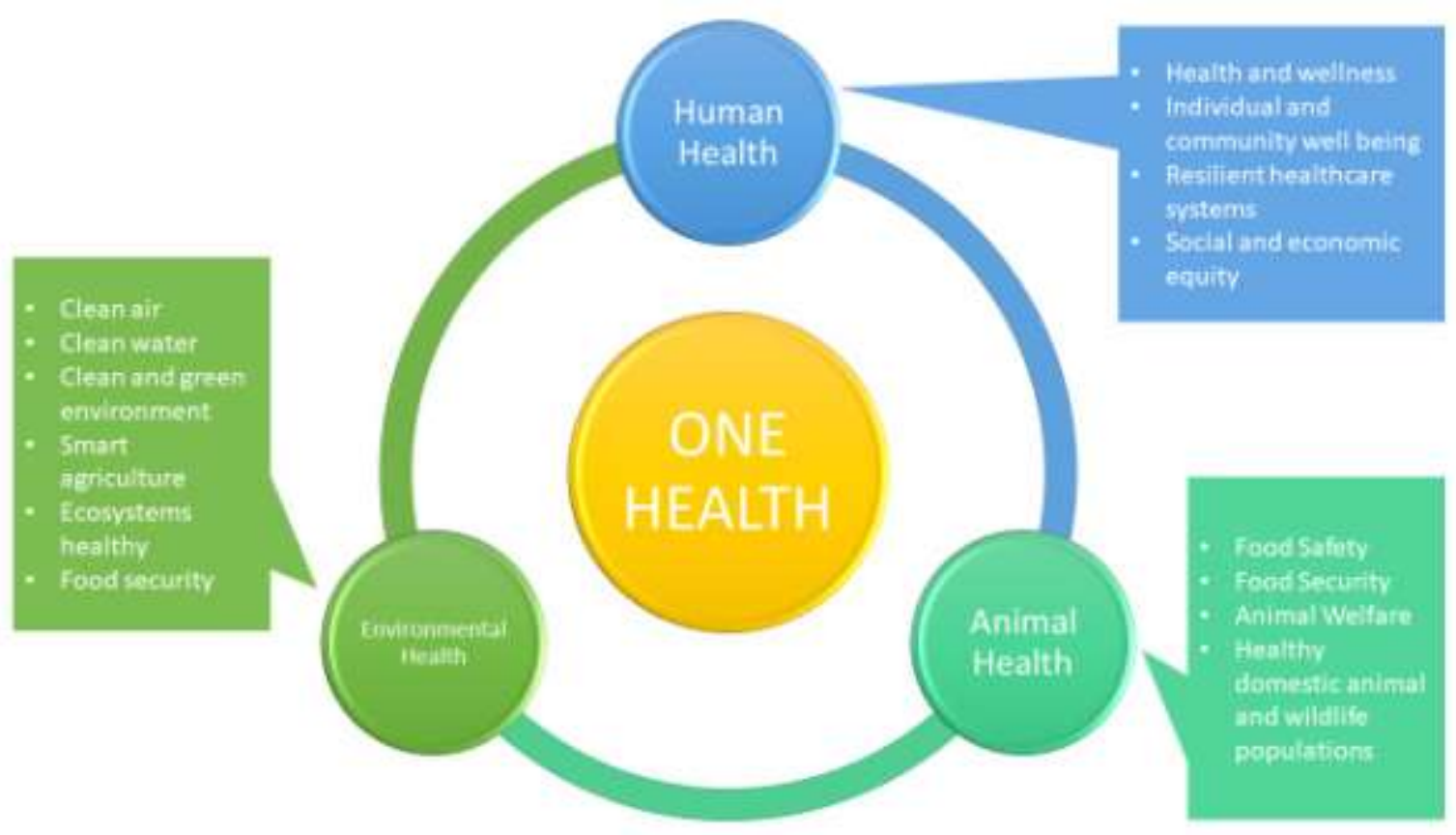

Figure 1. The three pillars of One Health and important global health outcomes within them.

\section{Conclusions}

The emergence of zoonotic infectious diseases is everyone's concern. The fate of humanitylies on how well we address the continuing emergence of pathogens that threaten our lives, health, and livelihood. The COVID-19 pandemic nearly crippled our world and our very existence. We were put in the very uncomfortable situation of looking at the effects of human environmental destruction and its dire effect on health without rose-colored glasses. Therefore, it is high time that humans look into efforts that prevent the emergence of these illnesses, rather than simply managing their effects. Addressing the problem through the lens of One Health is the way to go (Figure 1). The interconnections between human, animal, and environmental health should never be neglected and must be put into prime consideration in regional, national and international human development policies and thrusts. Through One Health, addressing issues that provide the catalysis for the emergence of zoonic infectious diseases in the human - animal - environment interfacewill have lasting benefitsin promoting global health in the long run.

\section{Acknowledgements}

This research did not receive any funding from any institution. The author would like to acknowledge the Philippine Department of Science and Technology- Accelerated Science and Technology Human Resource Development Program- National Science Consortium (DOST-ASTHRDP-NSC) Scholarship for funding his graduate studies.

\section{Conflict of Interest}

No conflict of interest to declare.

\section{References}

1) Athni TS, Shocket MS, Couper LI, Nova N, Caldwell IR, Caldwell JM, Childress JN, Childs ML, De Leo GA, Kirk DG, MacDonald AJ, Olivarius K, Pickel DG, Roberts SO, Winokur, OC, Young HS, Cheng J, Grant EA, Kurzner PM, Kyaw S, ... Mordecai EA. (2021). The influence of vector-borne disease on human history: socio-ecological echanisms. EcologyLetters 24: 829-846. https://doi.org/10.1111/ele.13675

2) Barbier EB. (2021). Habitat loss and the risk of disease outbreak. Journal of Environmental Economics and Management 108: 102451.

3) Bezerra-Santos MA, Mendoza-Roldan JA, Thompson R, Dantas-Torres F, Otranto D. (2021). Illegal Wildlife Trade: A Gateway to Zoonotic Infectious Diseases. Trends inParasitology 37: 181-184. https://doi.org/10.1016/j.pt.2020.12.005 
4) Bonilla-Aldana DK, Quintero-Rada K, Montoya-Posada JP, Ramírez-Ocampo S, Paniz-Mondolfi A, Rabaan AA, Sah R, Rodríguez-Morales AJ. (2020). SARS-CoV, MERS-CoV and now the 2019-novel CoV: Have we investigated enough about coronaviruses? - A bibliometric analysis. TravelMedicine and Infectious Diseases 33: 101566. https://doi.org/10.1016/j.tmaid.2020.101566

5) Chowdhury S, Hossain ME, Ghosh PK, Ghosh S, Hossain MB, Beard C, Rahman M, Rahman MZ. (2019). The Pattern of Highly Pathogenic Avian Influenza H5N1 Outbreaks in South Asia. TravelMedicine and Infectious Diseases 4: 138. https://doi.org/10.3390/tropicalmed4040138

6) Espinosa R, Tago D, Treich N. (2020). Infectious Diseases and Meat Production. Environmental andResourceEconomics 1-26. https://doi.org/10.1007/s10640-020-00484-3

7) Ferreira MN, Elliott W, Kroner RG, Kinnaird MF, Prist PR, Valdujo P, Vale MM. (2021). Drivers and causes of zoonotic diseases: an overview. Parks 27: 15-24.

8) Frutos R, Gavotte L, Serra-Cobo J, ChenT, Devaux C. (2021). COVID-19 and emerging infectious diseases: The society is still unprepared for the next pandemic. EnvironmentalResearch 202: 111676. https://doi.org/10.1016/j.envres.2021.111676

9) Goenka A, Liu L. (2020). Infectious diseases, human capital and economic growth. EconomicTheory 70: 1-47.

10) Greenhalgh T, Jimenez JL, Prather KA, Tufekci Z, Fisman D, Schooley R. (2021). Ten scientific reasons in support of airborne transmission of SARS-CoV-2. Lancet 397:1603-1605. https://doi.org/10.1016/S01406736(21)00869-2

11) Gong B, Zhang S, Liu X, Chen KZ. (2021). The Zoonotic diseases, agricultural production, and impact channels: Evidence from China. GlobalFoodSecurity 28: 100463. https://doi.org/10.1016/j.gfs.2020.100463

12) Levkovich SA, Rencus-Lazar S, Gazit E, Laor Bar-Yosef D. (2021). Microbial Prions: Dawn of a New Era. Trends in Biochemical Sciences 46: 391-405. https://doi.org/10.1016/j.tibs.2020.12.006

13) Oboho IK, Tomczyk SM, Al-Asmari AM, Banjar AA, Al-Mugti H, Aloraini MS, Alkhaldi KZ, Almohammadi EL, Alraddadi BM, Gerber SI, Swerdlow DL, Watson JT, Madani TA.(2015). 2014 MERS-CoV outbreak in Jeddah--a link to health care facilities. New England Journal of Medicine 372: 846-854. https://doi.org/10.1056/NEJMoa1408636

14) OeschgerTM, McCloskey DS, Buchmann RM, Choubal AM, Boza JM, Mehta S, Erickson D. (2021). Early Warning Diagnostics for Emerging Infectious Diseases in Developing into Late-Stage Pandemics. Accounts of Chemical Research 54: 3656-3666. https://doi.org/10.1021/acs.accounts.1c00383

15) Platto S, Zhou J, Wang Y, Wang H, Carafoli E. (2021). Biodiversity loss and COVID-19 pandemic: The role of bats in the origin and the spreading of the disease.Biochemical and Biophysical Research Communications 538: 2-13. https://doi.org/10.1016/j.bbrc.2020.10.028

16) Rohr JR, Barrett CB, Civitello DJ, Craft ME, Delius B, DeLeo GA, Hudson PJ, Jouanard N, NguyenKH, Ostfeld RS, Remais JV, Riveau G, Sokolow SH, Tilman D. (2019). Emerging human infectious diseases and the links to global food production. NatureSustainability 2: 445-456. https://doi.org/10.1038/s41893-0190293-3

17) Spencer JNH, Marasco D, Eichinger M. (2021). Planning for Emerging Infectious Disease Pandemics: Definitions, the Role of Planners, and Learning From the Avian Influenza Outbreak of 2004-2005. Journal of theAmerican Planning Association.https://doi.org/10.1080/01944363.2021.1930107

18) Taylor LH, Latham SM, Woolhouse ME. (2001). Risk factors for human disease emergence. Philosophical Transactions of the Royal Society B: Biological Sciences 356: 983-989.https://doi.org/10.1098/rstb.2001.0888

19) Tenorio JCB, Flores V II D. (2021). Campylobacter jejuni From Farm to Fork: Campylobacteriosis and Chicken Meat. Journal ofCurrentScience andTechnology11: 458-468.www.doi.org/10.14456/jcst.2021.45

20) Tenorio JCB, Molina EC. (2021a). Schistosoma japonicum in the Philippines: Its epidemiology, diagnostics, control, and elimination. Journal of Agricultural Research, Development and Extension 3: 71-87.

21) Tenorio JCB, Molina EC. (2021b). Monsters in our food: Foodborne trematodiasis in the Philippines and beyond.Veterinary Integrative Sciences19: 467-485

22) Van Oosterhout C. (2021). Mitigating the threat of emerging infectious diseases; a coevolutionary perspective. Virulence 12: 1288-1295. https://doi.org/10.1080/21505594.2021.1920741

23) Williams EP, Spruill-Harrell BM, Taylor MK, Lee J, Nywening AV, Yang Z, Nichols JH, CampJV, Owen RD, Jonsson CB. (2021). Common Themes in Zoonotic Spillover and Disease Emergence: Lessons Learned from Bat- and Rodent-Borne RNA Viruses. Viruses 13: 1509. https://doi.org/10.3390/v13081509 